\title{
Desain media informasi Taman Samarendah di Samarinda
}

\author{
Andi Farid Hidayanto, ${ }^{1 *}$ Nur Husniah Thamrin ${ }^{2}$

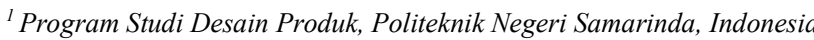 \\ ${ }^{2}$ Program Studi Arsitektur, Politeknik Negeri Samarinda, Indonesia
}

\begin{abstract}
Samarendah Park is one of the new icons in Samarinda City. Its function has been felt by the people of Samarinda since it opened. This park can be used as a place to exercise, play children, or just relax. Now the park which is in the center of Samarinda City preening becomes increasingly beautiful. Taman Samarendah is reorganized so that it can be enjoyed more and more by Samarinda residents and tourists. Therefore, a signage is needed that is used to make information that guides the place and appeals. The purpose of this design is to make an information board that can provide information about Samarendah Park and facilities around the park. In this design process using the Vinod Ghoel method which includes Preliminary Design, Design Development, Final Design \& Prototype. This design produces a product that is the Samarendah park information board. With the existence of the Samarendah park information board, it is hoped that it can facilitate access to information on places and appeals on location for visitors.
\end{abstract}

Key words: board, information, Samarendah

\begin{abstract}
Abstrak
Taman Samarendah adalah salah satu ikon baru di Kota Samarinda. Fungsinya sudah dirasakan oleh warga Samarinda sejak dibuka. Taman ini dapat dijadikan sebagai tempat berolahraga, bermain anak, atau sekedar bersantai. Kini taman yang berada di pusat Kota Samarinda ini bersolek menjadi semakin cantik. Taman Samarendah ditata kembali agar dapat dinikmati oleh warga Samarinda dan para wisatawan. Oleh karena itu, dibutuhkan sebuah papan informasi yang digunakan untuk memberikan informasi tentang petunjuk tempat dan himbauan di taman Samarendah. tujuan dari perancangan ini adalah membuat papan informasi yang dapat memberikan informasi tentang taman Samarendah dan fasilitas yang ada di sekitar taman. Dalam proses perancangan ini menggunakan metode Vinod Ghoel yang meliputi Preliminary Design, Design Development, Final Design \& Prototype. Perancangan ini menghasilkan sebuah produk yaitu papan informasi Taman Samarendah. Dengan adanya papan informasi Taman Samarendah ini diharapkan dapat memudahkan pengunjung untuk mengakses informasi tempat dan himbauan di lokasi bagi para pengunjung.
\end{abstract}

Kata kunci: media informasi, desain, Samarendah

\section{Pendahuluan}

Kota Samarinda merupakan Ibukota Kalimantan Timur. Kota Samarinda memiliki beberapa taman dengan berbagai sarana dan prasarana. Salah satunya adalah Taman Samarendah berada di pusat Kota Samarinda (Muthalib, 2021). Nama taman ini berasal dari penyebutan orang-orang terdahulu yang menyebut Samarinda menjadi Samarendah. Menurut versi Pemerintah Kota Samarinda, arti sebenarnya adalah taman yang tampak samar-samar dari kejauhan tapi indah dipandang (Saputri, Sulistyowati, $\&$ hanum, 2020). Taman Samarendah ini bisa dibilang taman yang baru di Kota Samarinda. Taman ini menjadi alternatif rekreasi keluarga. dengan menyuguhkan taman kota hijau, banyak pepohonan rimbun, juga dekat dengan tempat ibadah, yaitu masjid berlokasi ujung seberang taman. Taman ini juga menjadi tempat komunitas berkumpul seperti komunitas sepatu roda anak-anak, komunitas hewan, dan komunitas yang lainnya. Dengan arsitektur desain taman yang unik menjadi daya tarik kelebihan dari

\footnotetext{
* Corresponding author e-mail : andifarid@polnes.ac.id
} 
taman ini yang berlokasi ditengah Kota Samarinda tetapi taman jika tidak didukung dengan prasarana informasi yang memadai. Sebagai perbandingan, beberapa tulisan pernah mengkaji fasilitas publik dalam sebuah taman kota di beberapa kota di Indonesia, seperti Jakarta (Nursanto, 2011; Saragih \& Rachmawati, 2015), Tangerang (Imansari \& Khadiyanta, 2015), Banjarbaru (Widiastuti, 2013), Bandung (Setiawan et al., 2018), Bandar Lampung (Choirunnisa et al., 2017), dan Surabaya (Campoko, 2018), termasuk taman kota dalam konteks kota kreatif di Yogyakarta (Jayadi \& Prasetya, 2018). Dalam kasus ini, Taman Samarendah ditemukan belum memiliki fasilitas publik berupa signage yang memadai, sehingga berpotensi membingungkan para pengunjung (Karja, 2020). Sarana media informasi hanya tersedia di halaman Museum Samarinda yang berada di seberang jalan.

Dari penjelasan di atas, diperlukan suatu rancangan produk papan tanda baca untuk Taman Samarendah yang memudahkan pengunjung bernavigasi dalam sebuah taman yang mudah dipahami, dan memiliki bentuk yang estetis sehingga pengunjung tertarik untuk mengamatinya.

\section{Bahan dan metode}

Perancangan produk ini menggunakan metode dari Vinod Goel (Goel, 2014) yang merumuskan 3 tahapan perancangan, yakni: preliminary design, design develovment, final design \& prototype. Preliminary Design adalah tahap pengumpulan data dari informasi, analisis data berdasarkan konsep desain makro yang meliputi analisis konsep (konsep fungsi, konsep pemakaian, pemakaian pasar, dan konsep produk), penyusunan program desain sketsa awal. Bagian ini terdiri dari perumusan masalah dan tinjauan pustaka. Tahap yang kedua adalah Design Development. Pada tahap ini dibuat alternatif gambar komponen serta rancangan secara wire diagram dengan bentuk sketsa dari bagian yang tertera di atas terdiri dari beberapa alternatif desain, dan pengembangan alternatif desain. Sketsa-sketsa tersebut dianalisis kelebihan dan kekurangannya, dan apakah sudah memenuhi kriteria desain yang ditentukan. Langkah berikutnya adalah Final Design \& Prototype Pada tahap ini dibuat gambar-gambar dengan presentasi 3D dan gambar teknik (gambargambar tampak, potongan, gambar detail, dan spesifikasi teknik produk). Tahapan selanjutnya adalah pembuatan komponen-komponen dilakukan assembling (exploded) atau perakitan sehingga menjadi produk (prototype).

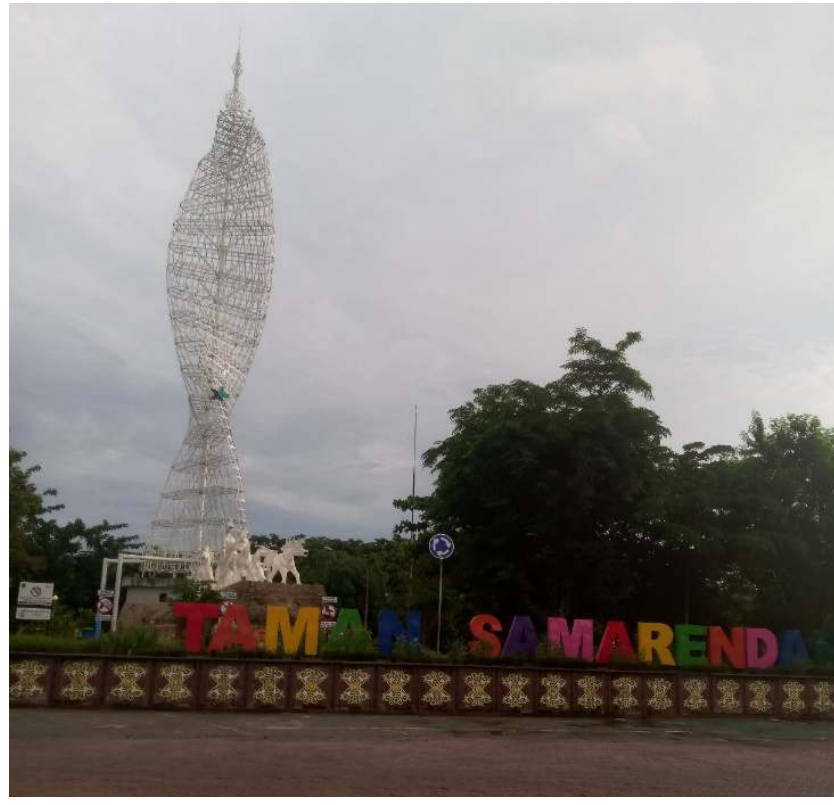

Gambar 1. Taman Samarendah

Sumber: Dokumentasi Pribadi

\section{Hasil dan pembahasan}

Analisis aktivitas dan kebutuhan dilakukan untuk mengetahui aktivitas yang dilakukan berkaitan dengan produk yang akan dibuat sehingga diperoleh daftar kebutuhan pengguna. Aktivitas yang terhimpun adalah melihat petunjuk dan rambu rambu himbauan, mengenali identitas Samarinda dan tempat berfoto. Berdasarkan analisis aktivitas dan kebutuhan yang telah dilaksanakan, serta keterangan tersebut, maka diperoleh kesimpulan mengenai komponenkomponen apa saja harus ada dalam produk. Berikut fasilitas yang terdapat produk, ialah: (1) Memiliki bidang datar untuk menempelkan huruf, dan himbauan; dan (2) Memiliki warna motif sarung Samarinda sebagai identitas Samarinda.

\section{Analisis Ergonomi dan Anthropometri}

Analisis ergonomi dilakukan untuk mengedepankan aspek kesehatan dan keselamatan dan juga agar kenyamanan dalam melakukan kegiatan menggunakan produk dapat maksimal. Ergonomi sangat diperlukan untuk merancang suatu produk. Aktivitas-aktivitas yang dianalisis membutuhkan fasilitas yang ergonomis agar kenyamanan pengguna ketika menggunakan produk dapat terjamin. Fokus pertimbangan aspek ergonomi dalam hal ini adalah kenyamanan dan keamanan yang diperlukan untuk melakukan aktivitas dengan produk papan informasi yaitu dengan menggunakan material yang tidak berbahaya untuk menghindari adanya sudut-sudut 
yang tajam pada setiap sisinya yang bersentuhan langsung dengan manusia (Nurmianto, 2004).

Setelah studi aktivitas dan kebutuhan produk, maka dapat ditentukan anthropometri yang perlu digunakan untuk produk papan informasi sehingga dapat suatu batasan dimensi produk. Anthropometri yang dibutuhkan, terutama berkaitan dengan tinggi signage dan lebar papan informasi sesuai hasil simulasi manequin pro yang didapatkan hasil berikut (Cahyadi, 2014). Dalam hal tinggi signage, bidang visual optimum saat membaca pengumuman dengan jarak $150 \mathrm{~cm}$ dari papan informasi Taman Samarendah adalah sebesar $210 \mathrm{~cm}$. Sehingga tinggi maksimal papan informasi Taman Samarendah yang digunakan adalah $195 \mathrm{~cm}$ (Gambar 2). Tinggi bidang visual optimal dari lantai yakni $90 \mathrm{~cm}$. Sedangkan dalam hal lebar papan informasi, ukuran yang digunakan adalah $5 \%$ persentil wanita dengan range vision optimum $118 \mathrm{~cm}$ untuk lebar maksimal produk. Sehingga ukuran yang dapat digunakan adalah $90 \mathrm{~cm}$. Ukuran tersebut diasumsikan sebagai lebar papan informasi (Gambar 3).

Yang berikutnya adalah analisis yang berkaitan dengan sistem. Analisis sistem dilakukan guna menentukan sistem yang akan digunakan pada produk papan informasi. Papan informasi ini menggunakan sistem perancangan yang sama dengan mebel pada umumnya. Sistem yang dianalisis terutama yang terkait dengan sistem sambungan, sistem sambung akrilik dengan komposit, sistem sambungan besi dengan tanah, dan sistem finishing. Berikut ringkasan analisisnya.

Sistem Sambungan. Dari beberapa analisis sistem sambungan yang telah dilaksanakan, maka sistem sambungan las yang dipilih untuk diaplikasikan pada perancangan produk ini. Sistem sambungan las untuk menghubungkan komponen-komponen yang sifatnya permanen. Keuntungan menggunakan teknik las adalah menghasilkan sambungan yang permanen dan lebih kuat jika menggunakan teknik pengelasan yang tepat. Kekurangan dari teknik las ini adalah hasil las sulit dibongkar karena hasil dari pengelasan merupakan sambungan permanen sehingga jika konstruksi las ingin diganti maka konstruksi tersebut harus rusak (Siswanto, 2011). Tetapi hal ini memang sudah diperhitungkan, mengingat media papan sarana informasi ini merupakan fasilitas umum, yang akan bersentuhan dengan banyak orang dengan karakter berbeda-beda, sehingga kekuatan menjadi prioritas utama.

Sistem Sambung Akrilik dengan Komposit. Dari beberapa analisis sistem sambungan akrilik dengan komposit, maka sistem perekat dengan lem Acrylic
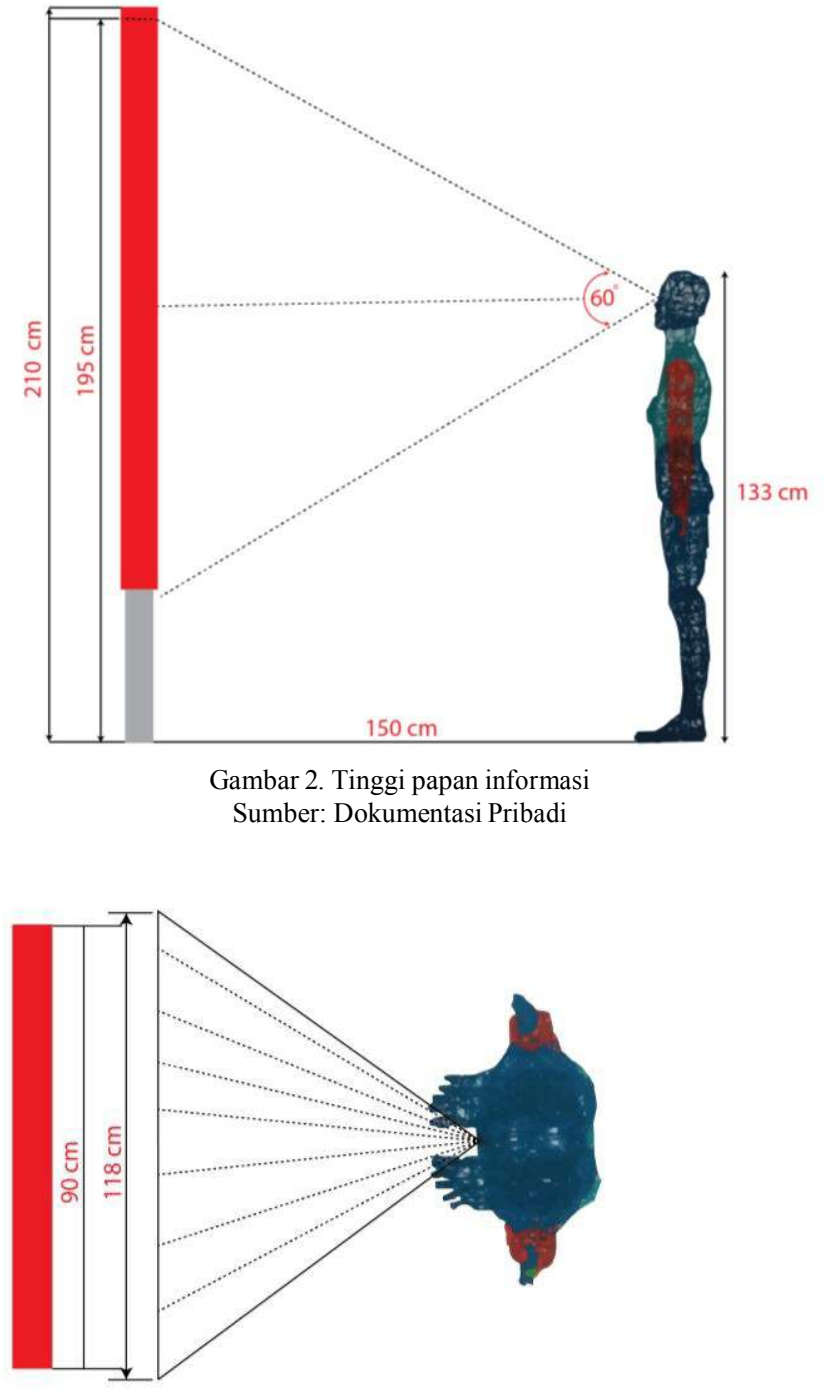

Gambar 3. Lebar papan informasi Sumber: Dokumentasi Pribadi

yang dipilih untuk diaplikasikan pada perancangan produk. Sistem sambungan menggunakan lem Acrylic mudah untuk digunakan pada proses pengerjaannya dan cocok untuk menghubungkan komponen-komponen yang sifatnya permanen. Perekat akrilik adalah bahan pengikat yang terbuat dari polimerisasi asam akrilik. Sistem menggunakan lem acrylic untuk menghubungkan akrilik dengan komposit yang sifatnya permanen. Sistem ini cocok untuk digunakan pada material akrilik yang di tempelkan di komposit.

Sambungan Besi dengan Tanah. Sambungan dengan semen diaplikasikan pada bagian alas papan informasi taman Samarendah. Semen sangat baik dalam menahan produk tersebut. Semen adalah suatu bahan yang apabila dicampur dengan air akan membentuk pasta kemudian mengeras dan setelah mengeras tidak larut kembali dalam air. Jadi bahan 
perekat hidrolis akan bersifat sebagai perekat apabila berhubungan dengan air. Dengan ditanam ke tanah menggunakan semen, produk akan berdiri kokoh, sehingga tidak bisa dipindah/diangkat oleh orang yang tidak bertanggung jawab, karena untuk memindahkannya harus merusak dengan membongkarnya.

Finishing. Dari analisis finishing yang telah dilaksanakan, cat dipilih untuk diaplikasikan ke produk papan informasi Taman Samarendah. Cat dipilih karena awet, cocok untuk outdoor dan harga yang lebih ekonomis. Cat sistem duco adalah jenis cat yang digunakan untuk teknik finishing dengan cara disemprotkan. Biasanya cat dan teknik yang satu ini digunakan untuk menggunakan aneka furnitur rumah dari bahan kayu seperti kursi, meja, dan lemari. Namun seiring perkembangan zaman dan teknologi, cat sistem duco juga mulai digunakan untuk finishing pintu, jendela, dinding, dan benda lain yang dibuat dari kayu atau besi. Kelebihan menggunakan cat duco adalah harga yang lebih ekonomis, awet, tahan lama serta tahan terhadap berbagai cuaca, dan menahan karat.

Analisis berikutnya berkaitan dengan material yang diaplikasikan. Analisis material dilakukan guna menentukan material baik yang akan digunakan pada produk sehingga menghasilkan produk yang aman dengan kegiatan pengguna. Terdapat beberapa jenis material yang digunakan kerena produk ini memiliki konsep eklektik, dimana perlu menggabungkan beberapa jenis material yang berbeda menjadi satu kesatuann dengan tampilan yang estetis. Berikut beberapa analisis material pada produk media papan informasi Taman Samarendah, terutama yang berkaitan dengan material rangka, material penutup rangka, dan material pendukung.

Material Rangka. Dalam memilih rangka yang syarat-syarat yang dipertimbangkan antara lain adalah material yang digunakan harus tahan lama, tahan korosi, tidak terlalu berat, ketersediaan barang di Samarinda dan biaya yang cukup murah. Dari hasil analisis material yang telah dilakukan, yang akan diaplikasikan pada produk adalah besi. Tekstur lapisan besi yang rapat, memiliki kekuatan yang baik dan tahan terhadap air.

Material Penutup Rangka. Dalam memilih penutup rangka, syarat-syarat yang dipertimbangkan antara lain harus tahan lama, tahan korosi, ketersediaan dan serta biaya yang cukup murah. Dari hasil analisis, material yang cocok untuk diaplikasikan pada produk yaitu plat alumunium. Plat aluminium ini kuat, tahan karat, ringan, memiliki tekstur halus.

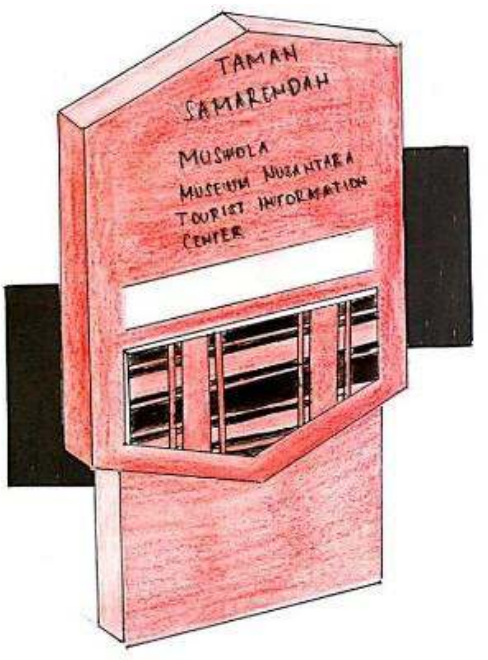

Gambar 4. Desain awal Sumber: Dokumentasi Pribadi

Material Pendukung. Pada material pendukung ini menggunakan akrilik untuk membuat motif sarung Samarinda. Penggunaan material akrilik karena lebih awet, mudah dalam perawatan, dan akrilik juga menambah dimensi pada papan informasi agar terlihat lebih menarik dan pada bagian petunjuk arah dan juga himbauan menggunakan cutting sticker. Digunakannya cutting sticker karena mudah dalam perawatan, bisa memantulkan cahaya dan juga harga lebih ekonomis.

Aspek bentuk merupakan analisis selanjutnya. Analisis bentuk diperlukan guna mencapai kenyamanan melalui bentuk yang sesuai dengan fungsi dan juga anatomi tubuh manusia terhadap produk papan informasi ini.Acuan dalam bentuk yang diinginkan serta dengan mempertimbangkan target konsumen yang dituju, yaitu semua umur dan dengan gaya hidup minimalis dan simpel serta dengan perilaku konsumen yang siang hari berolahraga dan pada malam hari berwisata. Dari beberapa acuan tersebut, ada beberapa bentuk gaya desain yang bisa menyesuaikan acuan studi kasus konsumen yang dapat diaplikasikan pada produk antara lain gaya desain modern, eklektik, minimalis dan motif etnik. Di antara bentuk gaya desain tersebut dipilih salah satunya melalui analisis yang mempertimbangkan aspek-aspek lainnya sebagai item penilaian yakni kemudahan pengerjaan serta kesesuaian target konsumen. Dari hasil analisis terpilih bentuk gaya desain modern karena kemudahan dalam pengerjaan, sesuai dengan target konsumen dan menggunakan motif sarung Samarinda yang mewakili Kota Samarinda, akan diaplikasikan pada produk ini. 


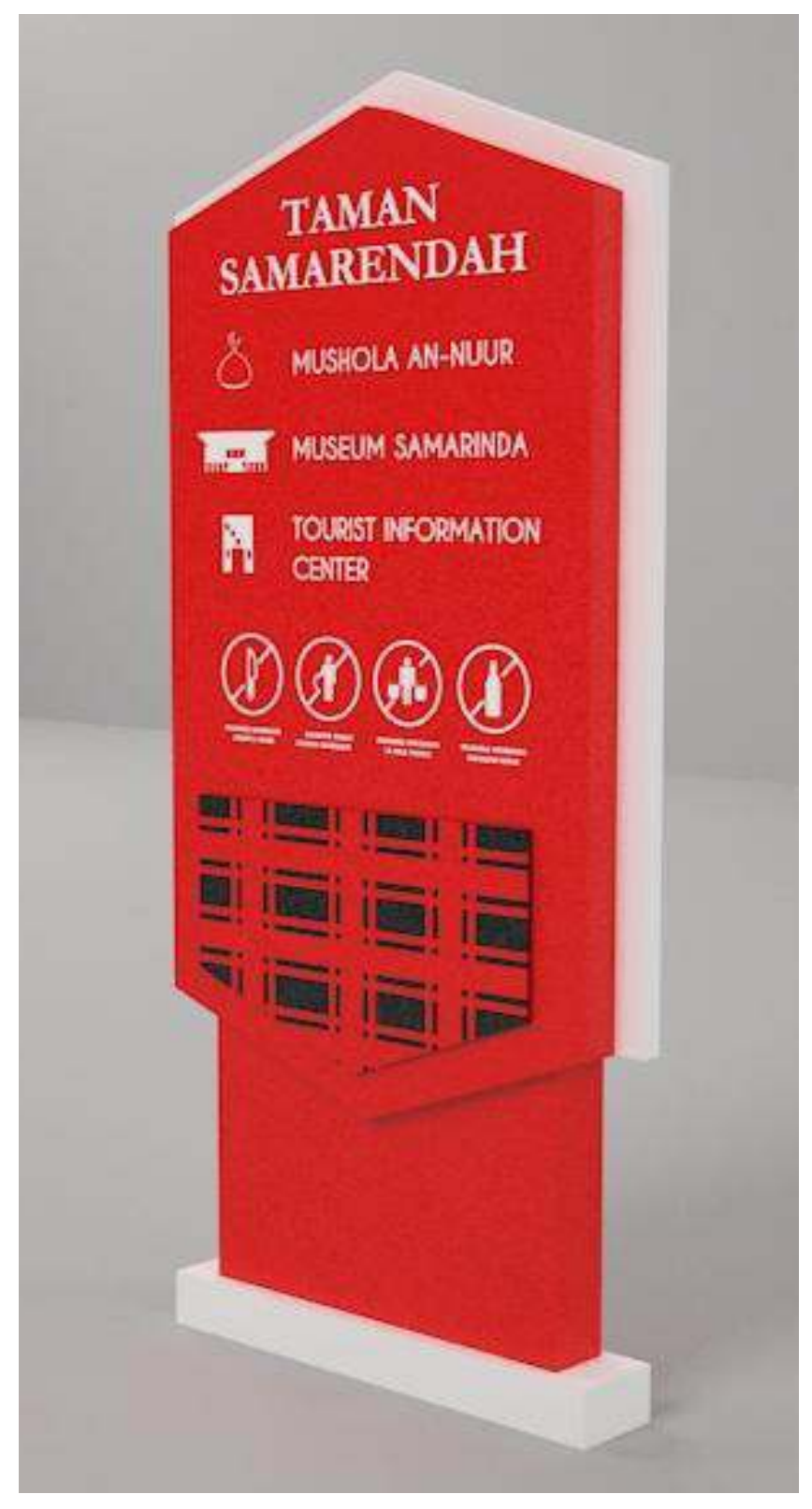

Gambar 5. Desain akhir Sumber: Dokumentasi Pribadi

Selain hal-hal di atas, salah satu unsur desain yang perlu dianalisis secara cermat adalah pemilihan warna. Warna memiliki karakteristik dan dampak estetis psikologis dalam desain. Analisis warna dilakukan untuk menemukan warna apa yang akan di aplikasikan pada produk, warna identitas Dayak, sign system dan warna modern. Berdasarkan analisis yang telah dilakukan, warna yang cocok digunakan untuk papan informasi adalah merah sebagai warna dominan. Warna merah dipilih karena warna tersebut memberi kesan menarik di antara warna dominan hijau, dan warna merah sebelumnya juga digunakan pada sign yang bertuliskan Taman Samarendah.

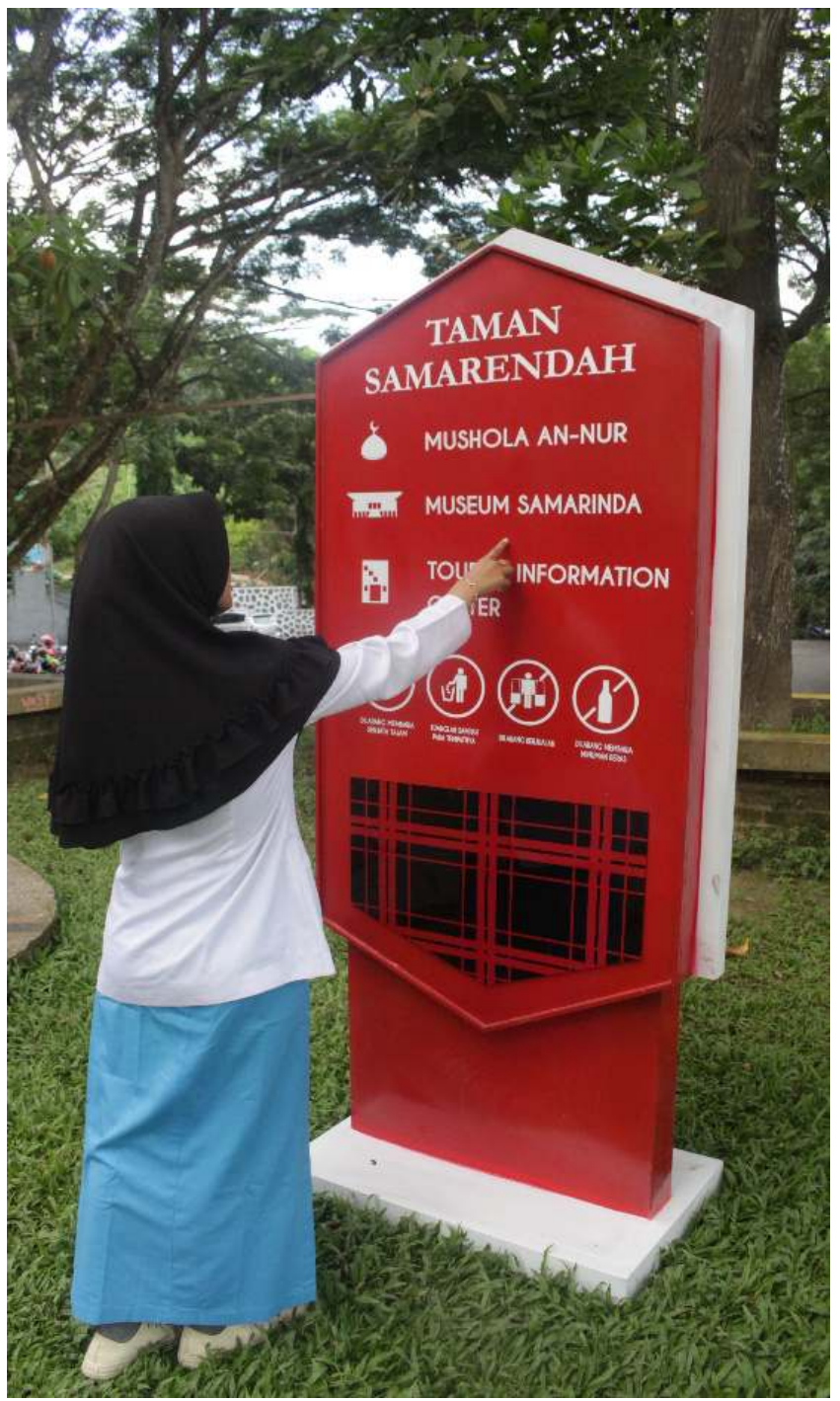

Gambar 6. Prototipe produk Sumber: Dokumentasi Pribadi

\section{Proses desain}

Dalam proses desain, langkah pertama yang dilakukan adalah membuat desain awal. Desaindesain awal tersebut selanjutnya dianalisis sesuai spesifikasi desain yang telah ditentukan. Dari beberapa alternatif desain, setelah dilaksanakan analisis, terpilih desain seperti yang ditunjukkan dalam Gambar 4.

Material yang digunakan adalah plat alumunium. Bagian petunjuk tempat dan juga himbauan menggunakan cutting sticker dan bagian motif sarung Samarinda menggunakan bahan akrilik. Pada bagian bawah produk kaki berbentuk persegi sehingga tidak membuang bahan. Desain awal terpilih tersebut selanjutnya dikembangkan menjadi beberapa alternatif pilihan. Alternatif-alternatif pengembangan tersebut selanjutnya dianalisis apakah memenuhi sesuai spesifikasi yang telah ditentukan, sehingga 
menghasilkan desain akhir. Hasil akhir yang diwujudkan dalam desain akhir tersebut diwujudkan seperti dalam Gambar 5. Hasil akhir tersebut dilengkapi dengan spesifikasi teknis, gambar presentasi, gambar kerja, gambar urai, modelling 3D yang nanti bisa diterjemahkan oleh tukang bila akan memproduksinya. Selanjutnya desain akhir tersebut dibuat prototipenya menjadi produk operasional seperti yang ditunjukkan dalam Gambar 5. Prototipe produk diperlihatkan dalam Gambar 6 .

\section{Penutup}

Berdasarkan hasil dari perancangan sarana informasi di Taman Samarendah, maka dapat ditarik kesimpulan sebagai berikut: (1) Tujuan pada perancangan produk ini adalah merancang sebuah papan sebagai media informasi tata letak bangunan di sekitar Taman Samarendah; (2) Sarana informasi di Taman Samarendah ini menggunakan konsep gaya modern, dengan menggunakan warna identitas Dayak yaitu merah sebagai dominan merah dan warna putih sebagai aksen, dengan motif sarung Samarinda; (3) Sarana informasi Taman Samarendah ini pada petunjuk dan himbauan menggunakan material cutting sticker yang dapat memantulkan cahaya sehingga mudah dalam penggunaannya. Sarana informasi Taman Samarendah ini didesain menggunakan material plat alumunium yang tepat untuk kondisi outdoor karena memiliki kelebihan yaitu tahan korosi. Material rangka menggunakan besi dengan sistem sambungan las, dan penempatan ke lokasi dengan dicor semen ke tanah agar aman, tidak mudah dibongkar oleh pihak yang tidak bertanggung jawab.

Saran yang dapat diberikan bagi para produsen dan desainer agar perlu diadakan redesign untuk inovasi sistem papan informasi dan material yang digunakan pada produk, serta fungsi yang dapat disesuaikan dengan keinginan konsumen. Fungsi tambahan yang dapat dimasukan ke dalam produk, sehingga produk akan menjadi lebih baik.

\section{Daftar pustaka}

Cahyadi, D. (2014). Aplikasi Mannaquin Pro Untuk Desain Industri. Yogyakarta: Leutkaprio.

Campoko, D. (2018). Harapan pengunjung terhadap perbaikan fasilitas duduk Taman Flora Surabaya. Productum: Jurnal Desain Produk (Pengetahuan Dan Perancangan Produk), 3(4), 113-118.

Choirunnisa, B., Setiawan, A., \& Masruri, N. W. (2017). Tingkat kenyamanan di berbagai taman kota di Bandar Lampung. Jurnal Sylva Lestari, 5(3), 48-57.

Goel, V. (2014). Creative brains: designing in the real world. Front Hum Neurosci, 8, 241. doi:10.3389/fnhum.2014.00241

Imansari, N., \& Khadiyanta, P. (2015). Penyediaan hutan kota dan taman kota sebagai ruang terbuka hijau (RTH) publik menurut preferensi masyarakat di kawasan pusat Kota Tangerang. Jurnal Ruang, 1(3), 101-110.

Jayadi, N., \& Prasetya, R. D. (2018). Penguatan eksistensi kota kreatif melalui inovasi desain kamuflase menara BTS berbasis zonasi wilayah. Productum: Jurnal Desain Produk (Pengetahuan dan Perancangan Produk), 3(3), 101-106.

Karja. (2020). Taman Samarendah, Tempat Rekreasi dan Olahraga Gratis di Samarinda. Retrieved from https://kumparan.com/karjaid/taman-samarendah-tempatrekreasi-dan-olahraga-gratis-di-samarinda-1 sz5RdpyrXp/full

Muthalib, A. (2021). 10 Taman di Samarinda yang Cocok untuk Refreshing. Retrieved from https://www.celebes.co/borneo/taman-samarinda

Nurmianto, E. (2004). Ergonomi: Konsep Dasar dan Aplikasinya. Surabaya: Guna Widya.

Nursanto, A. (2011). Analisa Taman Menteng sebagai taman kota berdasarkan kriteria kualitas taman Jakarta Pusat. Planesa, 2(1), 212970.

Saputri, A. P., Sulistyowati, E. D., \& Hanum, I. S. (2020). Asalusul nama Kecamatan Sambutan di Kota Samarinda Tinjauan Antropolinguistik. Ilmu Budaya: Jurnal Bahasa, Sastra, Seni dan Budaya, 4(2), 188-200.

Saragih, P. R. H., \& Rachmawati, R. (2015). Penyediaan Ruang Publik Taman Kota Berbasis Teknologi Informasi Dan Komunikasi Dalam Mendukung Jakarta Smart City Di Taman Menteng, Jakarta Pusat. Jurnal Bumi Indonesia, 4(4).

Setiawan, T., Sintaningrum, S., \& Mirandia, D. (2018). Persepsi Publik Pada Pengelolaan Taman Kota Di Kota Bandung. Jurnal Wacana Kinerja: Kajian Praktis-Akademis Kinerja Dan Administrasi Pelayanan Publik, 20(1), 73-90.

Siswanto. (2011). Konsep Dasar Teknik Las. Jakarta: PT Prestasi Pustakarya.

Widiastuti, K. (2013). Taman kota dan jalur hijau jalan sebagai ruang terbuka hijau publik di Banjarbaru. Modul, 13(2), 5764. 